\title{
Distribution of Cardiovascular Risk Factors in Patients with Psoriasis
}

\author{
ANA MARIA ALEXANDRA STANESCU1*, IOANA VERONICA GRAJ DEANU ${ }^{1}$, BOGDAN SERBAN ${ }^{12}$, CAMELIA CRISTINA DIACONU ${ }^{1,3}$ \\ IUniversity of Medicine and Pharmacy Carol Davila, 8 Eroii Sanitari Str, Bucharest, 050474, Bucharest, Romania \\ ${ }^{2}$ Emergency University Hospital Bucharest, 169 Splaiul Independentei, 050098, Bucharest, Romania \\ ${ }^{3}$ Clinical Emergency Hospital of Bucharest, 8 Calea Floreasca, 014461, Bucharest, Romania
}

\begin{abstract}
Psoriasis is a chronic inflammatory systemic disorder that associates many cardiovascular comorbidities. The association between psoriasis and cardiovascular disease is a complex one, which implies many risk factors, such as age, gender, heredity, smoking, alcohol and stress. The prognosis of patients with psoriasis may be improved by identifying and reduction of these cardiovascular risk factors. The objective of our study was to determine the prevalence of cardiovascular risk factors among patients with psoriasis from Bucharest and Ilfov county, Romania. 634 individuals from the general population were initially included. From these individuals, 208 patients with psoriasis have been selected for inclusion in our observational study. The patients were selected from Elias Emergency Hospital of Bucharest, Romania, and through the family doctors praxis, between 2010-2017. Of the 634 individuals from the general population, 208 patients (33\%) were identified as patients with a diagnosis of vulgar psoriasis, confirmed by the dermatologist, forming the study group. The presence of risk factors is consistent with the presence of cardiovascular disease (23\%) in the studied group. Patients with psoriasis, without cardiovascular diseases, have an increased risk of developing them throughout their lives. Patients with psoriasis have a very high risk of developing life-long cardiovascular disease, because of a multitude of risk factors associated with psoriasis. Intervention on modifiable risk factors for cardiovascular disease can be mediated by a family doctor, who can monitor the development over time and may also intervene early when appropriate.
\end{abstract}

Keywords: psoriasis, cardiovascular diseases, metabolic syndrome.

The prevalence of psoriasis varies by country, varying between $0.09 \%$ and $11.4 \%[1,2]$. The death of these patients generally does not occur because of psoriasis, but rather because of associated co-morbidities, especially cardiovascular events [3-5]. Globally, in 2016 stroke was ranked as the second cause of death $(10.2 \%)$ after ischemic heart disease. In Romania, in 2016, of the total population of $19,778,000$ inhabitants, 43,100 of the deaths were caused by stroke (19,200 men and 23,900 women) [6].

Psoriasis is a systemic chronic inflammatory disease associated with several comorbidities: cardiovascular disease, metabolic syndrome, diabetes, obesity, dyslipidemia [7,8]. The association between psoriasis and cardiovascular disease is a complex one that implies many risk factors. Age, gender, heredity, smoking, alcohol and stress are among these risk factors [9].

The association of psoriasis with cardiovascular risk factors is most likely based on genetic, immunological and environmental factors. These factors (Th1 and Th17 activation, proinflammatory cytokines and oxidative stress) induce endothelial dysfunction, promoting leukocyte adhesion and favoring a prothrombotic state [10]. The distribution of cardiovascular risk factors in patients with psoriasis must be evaluated, in order to determine the risk of cardiovascular disease and to apply preventive strategies. The relationship between psoriasis and cardiovascular risk factors is controversial. Some studies have reported differences in these risk factors, which may occur due to geographical area, diet and other factors. In Romania, one such study was carried out in Brasov city [11].

The objective of our study was to determine the prevalence of cardiovascular risk factors among patients with psoriasis from Bucharest and Ilfov county.

\section{Experimental part}

Materials and method

634 individuals from the general population were initially included. From these individuals, 208 patients with psoriasis have been selected for inclusion in our observational study. The patients included were selected from Elias Emergency Hospital of Bucharest, Romania, and through the family doctors praxis, between 2010-2017. Patients with a diagnosis of psoriasis confirmed by the dermatologist in the observation sheet or in the medical letter, as well as those newly diagnosed during the evaluation period, were included in the study. Only adult patients were included in the study (over 18 years old). Those who, because of psychiatric disorders, were unable to sign the informed consent were excluded.

The parameters studied were: age, sex, heredocollateral history, personal pathological history, severity of psoriasis according to Body Surface Area (BSA) [12], relapses, smoking, alcohol consumption, prevalence of stress, physical activity, waist circumference $(\mathrm{cm})$, body mass index (BMI) $\left(\mathrm{kg} / \mathrm{m}^{2}\right)$, systolic blood pressure $(\mathrm{mm}$ $\mathrm{Hg})$, diastolic blood pressure $(\mathrm{mm} \mathrm{Hg})$, serum glucose $(\mathrm{mg} /$ $\mathrm{dL})$, glycosylated hemoglobin (mg/dL), HOMA-IR, HDL cholesterol $(\mathrm{mg} / \mathrm{dL})$, triglycerides $(\mathrm{mg} / \mathrm{dL})$, vitamin $\mathrm{D}(\mathrm{ng} /$ $\mathrm{mL})$, fibrinogen $(\mathrm{mg} / \mathrm{dL})$, C reactive protein $(\mathrm{mg} / \mathrm{L})$, calcium $(\mathrm{mg} / \mathrm{dL})$.

The statistical analysis was performed by entering all the data obtained in Microsoft Excel, for analysis and processing. The coefficient interval of $95 \%$ has been respected for the variance ranges of the studied parameters. The selected $P$ value for considering differences as statistically significant in all analyses was $P$ $<0.05$.

*email: alexandrazotta@yahoo.com 


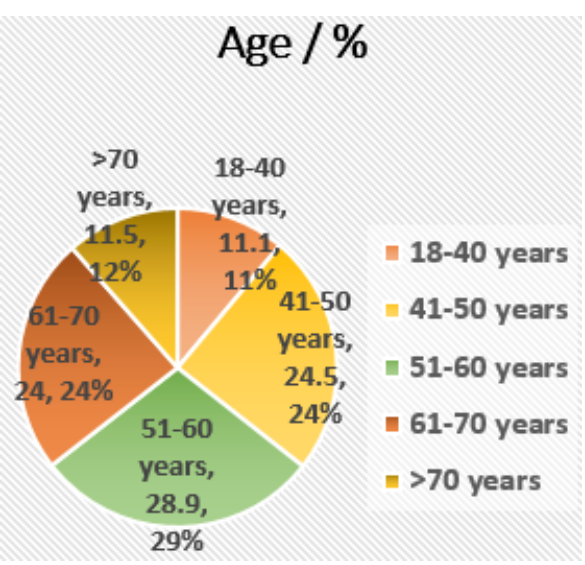

Distribution by sex

Fig. 1. Prevalence of psoriasis by age and sex

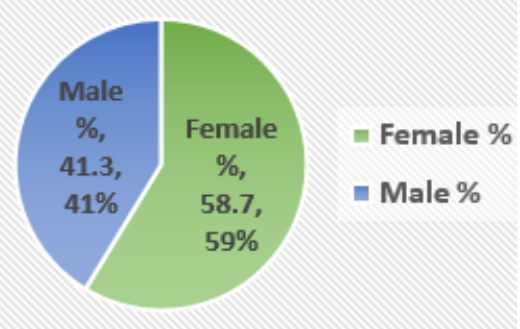

\section{Results and discussions}

Of the 634 individuals from the general population, 208 patients (33\%) were identified as patients with a diagnosis of vulgar psoriasis, confirmed by the dermatologist, forming the study group.

Depending on age, the following categories were selected: $18-40$ years -23 patients (11.1\%), $41-50$ years 51 patients $(24.5 \%), 51-60$ years -60 patients $(28.9 \%), 61-$ 70 years -50 patients $(24.0 \%)$, > 70 years -24 patients (11.5\%) (fig. 2).

\section{Severity of psoriasis}

- Severe $\%=$ Moderate $\%=$ Milde $\%$

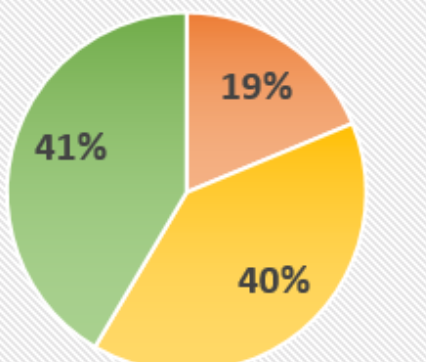

Relapses \%

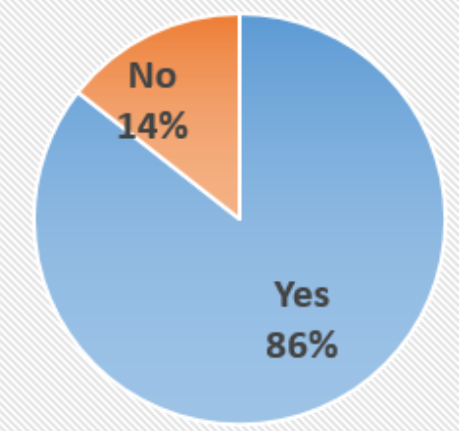

Fig. 2. Distribution of the severity of psoriasis and the history of relapses
The highest prevalence of psoriasis in the study group was encountered in the 51-60 year-old group. However, due to the distribution, it can be concluded that the prevailingage in psoriasis is between 41 years and 70 years.

Many studies report close proportions in gender distribution. Distribution by gender did not influence the results of the study.

\section{Heredo-collateral history in the studied group}

The distribution of heredo-collateral history highlights the increased incidence of cardiovascular disease (25.5\%) in the families of patients with psoriasis. The distribution of heredo-collateral history in patients with psoriasis follows the increasing trend of cardiovascular disease, occupying the first place in heredo-collateral history.

Psoriasis was diagnosed in $23.1 \%$ of the patients. Obesity, arthritis and diabetes have a higher frequency in the families of patients with psoriasis, the rest of the heredo-collateral history having no statistical significance for the study (table 1).

Table 1

FREQUENCY OF HEREDO-COLLATERAL ANTECEDENTS IN PATIENTSWITH PSORIASIS

\begin{tabular}{|l|l|c|}
\hline No & \multicolumn{2}{|c|}{ Heredo-collateral history } \\
\hline 1 & $\begin{array}{l}\text { Cardiovascular } \\
\text { diseases }\end{array}$ & $53 \mathrm{~N}(25.5 \%)$ \\
\hline 2 & Psoriasis & $48 \mathrm{~N}(23.1 \%)$ \\
\hline 3 & Obesity & $43 \mathrm{~N}(20.7 \%)$ \\
\hline 4 & Arthritis & $40 \mathrm{~N}(19.2 \%)$ \\
\hline 5 & Diabetes & $37 \mathrm{~N}(17.8 \%)$ \\
\hline
\end{tabular}

Regarding the correlations of psoriasis with heredocollateral history, there were found associations such as: in 11 cases (5\%) psoriasis and obesity, in 10 cases (4.8\%) psoriasis and cardiovascular diseases, in 9 cases (4.3\%) psoriasis and arthritis, psoriasis and diabetes in 7 cases (3.3\%), and in 5 cases (2.4\%) psoriasis with cardiovascular disease and obesity.

Personal pathological history of the studied group

From the pathological personal history, the association of psoriasis with cardiovascular disease was the most frequent (in $23.1 \%$ of cases), followed by $17 \%$ metabolic syndrome, $22.1 \%$ arthritis, $21.6 \%$ allergies, $13.9 \%$ diabetes, $3.4 \%$ neoplasms, other dermatological diseases $1.4 \%$, HIV/ AIDS $1 \%$ (table 2).

Table 2

\begin{tabular}{|c|l|c|}
\hline NO & $\begin{array}{l}\text { PSORIASIS ASSOCIATED } \\
\text { WITH: }\end{array}$ & $\begin{array}{c}\text { NUMBER OF } \\
\text { CASES } \\
\text { (PERCENTAGE) }\end{array}$ \\
\hline 1 & $\begin{array}{l}\text { CARDIOVASCULAR } \\
\text { DISEASES }\end{array}$ & $48(23 \%)$ \\
\hline $\mathbf{2}$ & METABOLIC SYNDROME & $36(17 \%)$ \\
\hline $\mathbf{3}$ & ALLERGIES & $31(15 \%)$ \\
\hline $\mathbf{4}$ & ARTHRITIS & $28(13 \%)$ \\
\hline $\mathbf{5}$ & DIABETES & $23(11 \%)$ \\
\hline $\mathbf{6}$ & NEOPLASMS & $7(3 \%)$ \\
\hline $\mathbf{7}$ & $\begin{array}{l}\text { CARDIOVASCULAR } \\
\text { DISEASES + DIABETES }\end{array}$ & $10(5 \%)$ \\
\hline $\mathbf{8}$ & $\begin{array}{l}\text { CARDIOVASCULAR } \\
\text { DISEASES + ARTHRITIS }\end{array}$ & $9(4 \%)$ \\
\hline
\end{tabular}


In our study, we diagnosed 57 other patients with psoriasis as having metabolic syndrome. In total, there were 105 patients $(50.5 \%)$ with psoriasis who had metabolic syndrome (from the 208 patients).

No significant correlations were found between psoriasis and personal physiological history. Association of psoriasis and gestational diabetes has been reported in 9 cases. In the study group, we did not found psoriasis triggers related to menarche, nor significant changes at menopause.

\section{History of psoriasis}

We found that out of the 208 patients with psoriasis in the study group, 39 (18.8\%) had severe psoriasis, 83 (39.9\%) moderate psoriasis and $86(41.6 \%)$ mild psoriasis. To determine the severity of psoriasis, the BSA score was used.

Regarding the duration of the disease in patients with psoriasis, the average interquartile deviation was $7.00[4.00$, 9.00].

Two of the patients with psoriasis had undiagnosed old lesions, being highlighted as patients with new diagnosis of psoriasis, representing $1 \%$ of the study group.

The shortest disease duration ( $<1$ year) was recorded in the two newly diagnosed patients. The longest duration of the disease was 20 years, registered in only one patient. In the studied group, the mean duration of illness was 7.02 \pm 3.61 years.

Of the 208 patients with psoriasis, 4 of them performed skin biopsy in psoriatic disease over time.

We found a large majority of $85.6 \%$ who claimed they had relapses over time. There were no relapses in those who had a shorter duration of the disease and who had not yet entered remission.

The number of relapses differs from one patient to another (from 1 to 6 relapses) throughout the disease. A longer disease' duration predisposes to a higher number of relapses.

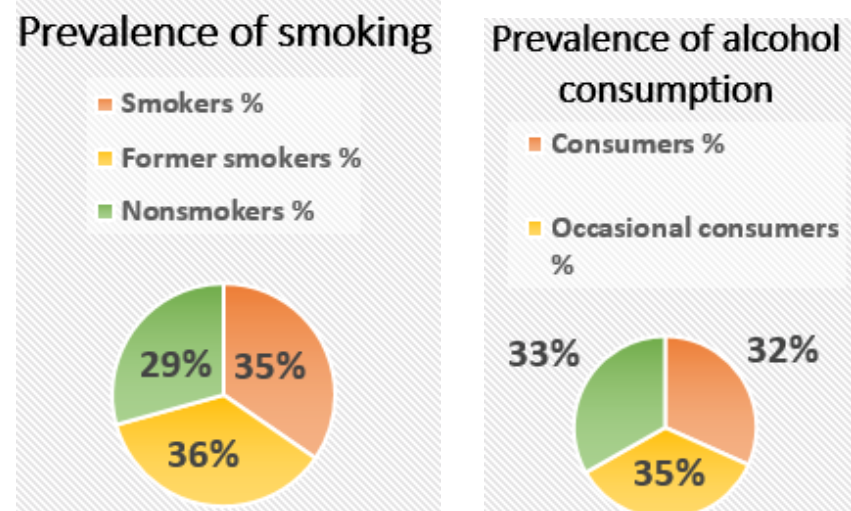

Fig. 3. Prevalence of smoking and alcohol consumption in the studied group.

In the group studied, the prevalence of smokers was as follows: 72 smokers, 75 former smokers and 61 nonsmokers.

Concerning alcohol consumption, 66 patients with psoriasis recognized frequent consumption, 73 occasionally and 69 denied alcohol consumption (fig. 3).

In this study, coffee / coca cola consumption, as triggering and aggravating factors, was found in 128 patients $(65.1 \%)$ of the 208 psoriasis patients.

The toxic working environment or conditions that may have a negative influence on psoriasis were reported by only $3.8 \%$ of patients.

In the current study, we found that stress is an important factor in psoriasis, high stress being reported by $52.4 \%$ of the patients, moderate stress by $28.4 \%$ and reduced stress

\section{Prevalence of stress}

= Intens \% $=$ Moderate $\%$ = Minimum \%

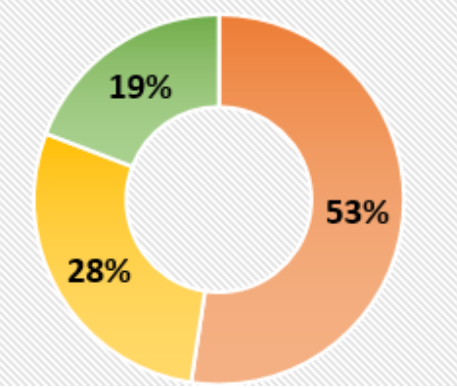

Physical activity

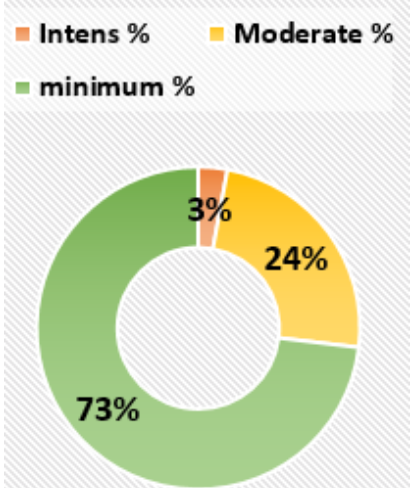

only by $19.2 \%$. Analyzing the worsening conditions of psoriasis, $21.2 \%$ associated worsening with the stressful periods of life.

Regarding physical activity, according to reports of patients with psoriasis, this was reduced in $73.1 \%$, who reported minimal physical activity, 34\% moderate physical activity and only $2.9 \%$ intense physical activity.

For a better analysis of the serum vitamin $D$ data, we took into account both the season and the exposure to sunlight of each patient in the study group.

\section{Sun exposure}

- High exposure \%

Average exposure \%

- Minimum exposure \%

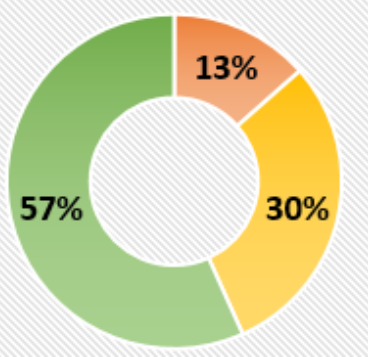

Use of sunscreen
Fig. 5. The degree of sun exposure and the use of sunscreen
- Frequently $\%$ - Occasional $\%$ - Not used $\%$

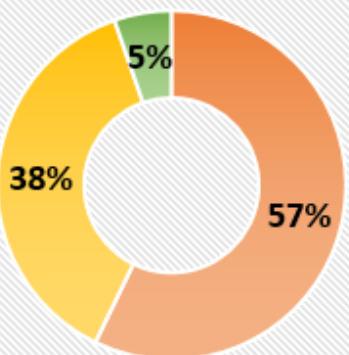




\begin{tabular}{|l|c|}
\hline \multicolumn{1}{|c|}{ PARAMETER } & $\begin{array}{c}\text { MEAN } \pm \text { STANDARD } \\
\text { DEVIATION (SD) / MEAN } \\
\text { INTERQUARTILE DEVIATION }\end{array}$ \\
\hline Waist circumference (cm) & $103.67 \pm 18.916$ \\
& $101.5[18.9,120.0]$ \\
\hline BMI(kg/m2) & $28.27 \pm 5.091$ \\
& $27.0[25.0,31.0]$ \\
\hline Systolic blood pressure (mm HG) & $150.61 \pm 11.065$ \\
& $149.0[140.7,155.7]$ \\
\hline Diastolic blood pressure (mm HG) & $88.43 \pm 3.992$ \\
& $87.0[86.0,89.0]$ \\
\hline Glucose (mg/dL) & $105.19 \pm 29.242$ \\
& $96.0[84.0,125.0]$ \\
\hline Glycosylated hemoglobin (mg/dL) & $6.33 \pm 0.696$ \\
& $6.3[5.9,6.8]$ \\
\hline HOMA-IR & $2.84 \pm 1.234$ \\
& $2.3[1.9,3.4]$ \\
\hline HDL cholesterol (mg/dL) & $44.11 \pm 12.434$ \\
& $44.0[34.0,53.7]$ \\
\hline Triglycerides (mg/dL) & $147.36 \pm 26.837$ \\
& $141.0[130.5,161.7]$ \\
\hline Vitamin D (ng/ml) & $28.25 \pm 19.130$ \\
& $23.0[14.0,37.7]$ \\
\hline
\end{tabular}

Table 3

PARAMETERS TRACKED AS MEAN \pm STANDARD DEVIATION (SD) / MEAN INTERQUARTILE. DEVIATION.
We also considered the use of solar protection which, depending on the degree of protection, may completely or partially block the production of D3 previtamin.

In the studied group, the lowest waist circumference was $59 \mathrm{~cm}$ and the highest $142 \mathrm{~cm}$, and the BMI was from 17 to $42 \mathrm{~kg} / \mathrm{m}^{2}$.

Of the 208 patients with psoriasis, we found 2 underweight patients with an average BMl of $17.5 \mathrm{Kg} / \mathrm{m}^{2}$, 39 normal weight patients with an average BMI of 22.38 $\mathrm{Kg} / \mathrm{m}^{2}, 100$ overweight patients with an average BMI of $26.82 \mathrm{Kg} / \mathrm{m}^{2}$ and 65 patients with obesity grade I, II and III, with an average BMI of $34.36 \mathrm{Kg} / \mathrm{m}^{2}$ (fig. 6).

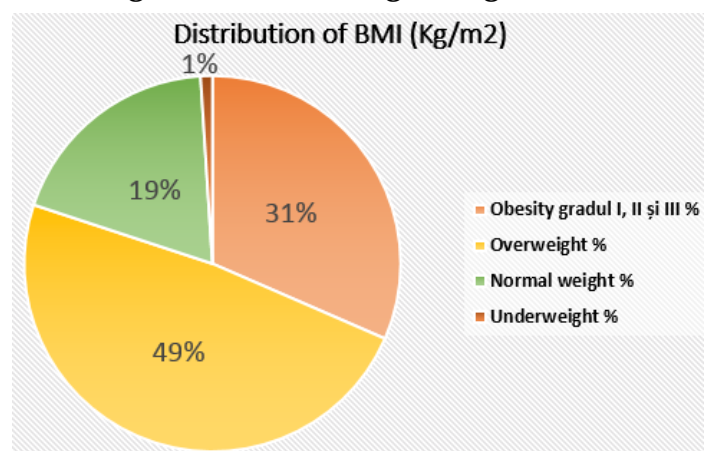

Fig. 6. Graphic percentage representation of BMI $\left(\mathrm{Kg} / \mathrm{m}^{2}\right)$ distribution

We found variations in systolic and diastolic blood pressure, ranging from $137 \mathrm{mmHg}$ to $179 \mathrm{mmHg}$, and from $84 \mathrm{mmHg}$ to $100 \mathrm{mmHg}$, respectively.

The following biological parameters were evaluated in the study: glycemia, glycosylated hemoglobin, HOMA-IR, $\mathrm{HDL}$ cholesterol, triglycerides and vitamin $\mathrm{D}$ are shown in table 3 , in the form of mean \pm standard deviation (DS).

Inflammatory markers were measured. In the group of patients with psoriasis, we found elevated erythrocyte sedimentation rate (ESR) values in $39.4 \%$ of the patients. Increased levels of fibrinogen, representing increased risk of coronary and cerebrovascular disease, were found in $47.6 \%$ of patients, while moderate risk of coronary and cerebrovascular disease was found in $46.2 \%$ of patients. The inflammatory process was highlighted in $49 \%$ of patients with elevated levels of $\mathrm{C}$ reactive protein (fig.7).

Low serum calcium levels were found in $49 \%$ of patients (fig. 8).

In this study, we noticed the presence of numerous cardiovascular risk factors in patients with psoriasis. The presence of risk factors is consistent with the presence of cardiovascular disease (23\%) in the studied group. Patients with psoriasis, without cardiovascular diseases, have an increased risk of developing them throughout their lives.

The prevailing age of patients with psoriasis in this study is between 41 years and 70 years, which indicates an increased risk of developing cardiovascular events. In terms of gender in psoriasis patients distribution, female gender prevails $(p<0.001)$ (Binominal test), with a percentage of $58.7 \%$, compared to the male (41.3\%). The risk of stroke increases with age, men's risk increases by $9 \%$ with each passing year and for women by $10 \%$ each year. However, the incidence of stroke is lower in women than in men [13]. In the elderly population, $80 \%$ of deaths occur due to cardiovascular disease, especially heart attack and stroke [14].

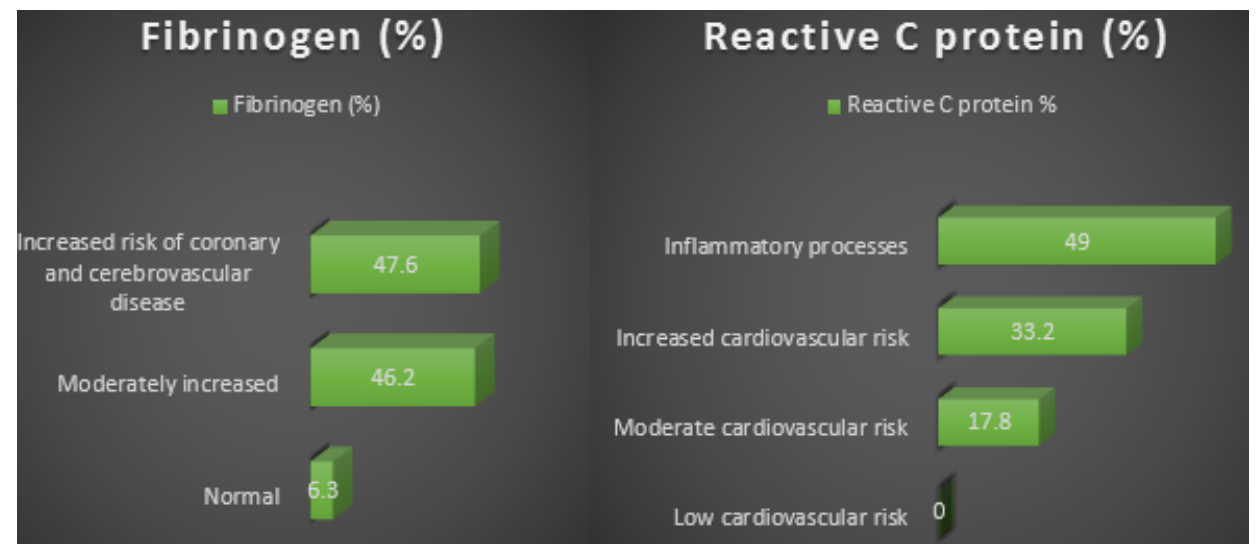

Fig. 7. Percentages of fibrinogen $(\mathrm{mg} /$ $\mathrm{dL})$ and the $\mathrm{C}$ reactive protein $(\mathrm{mg} / \mathrm{dL})$ 


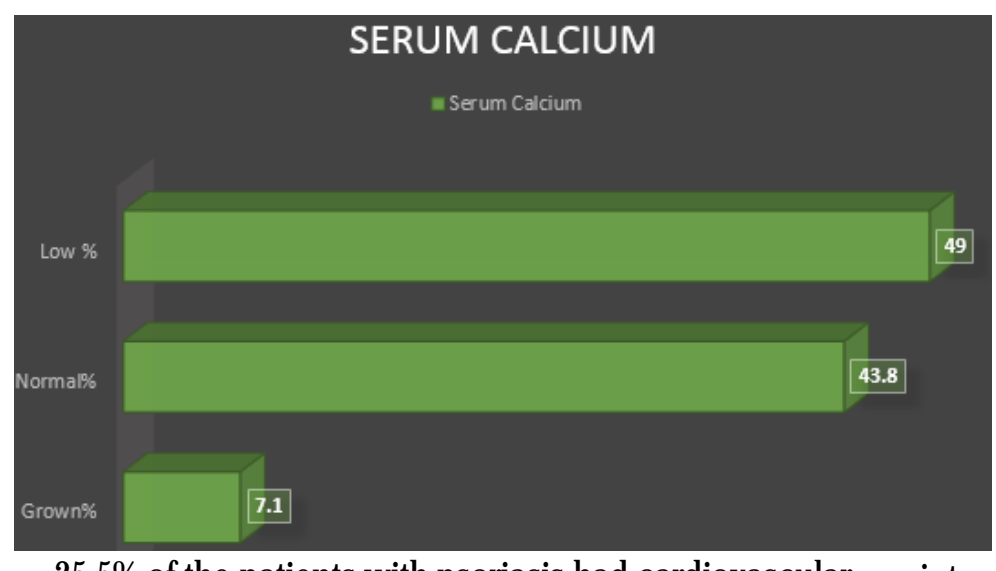

Fig. 8. Distribution of serum calcium values in the group of study.

$25.5 \%$ of the patients with psoriasis had cardiovascular disease in their heredo-collateral history, followed by psoriasis (23.1\%) and obesity (20.7\%).

Regarding pathological personal history, as expected, most often we met cardiovascular disease (23\%), followed by metabolic syndrome (17\%).

Other studies have shown that psoriasis is associated with cardiovascular disease, in particular coronary heart disease, peripheral artery disease (OR 1.98, 95\% Cl, 1.322.82), cerebrovascular disease $(\mathrm{OR}, 1.70 ; 95 \% \mathrm{Cl}, 1.33$ 2.17) [15]. The incidence of myocardial infarction in patients with severe psoriasis was $5.13(95 \% \mathrm{Cl}, 4.22-6.17)$ [16] and a significant increase in the risk of stroke has been observed (hazard ratio [HR], 1.43; 95\% Cl, 1.1-1.9) [17].

The severity of psoriasis (severe psoriasis in $19 \%$ of the study group), relapses ( $86 \%$ of the study group) and the mean years of illness ( $7.02 \pm 3.61$ years) are risk factors for cardiovascular disease. The higher the severity, the more relapses, and the longer the duration of the disease, the higher the chances of developing cardiovascular disease.

In this study, smokers and former smokers accounted for $71 \%$, alcohol consumption was encountered in $67 \%$ of the patients, caffeinated beverages consumption accounted for $65.1 \%$ (the amount of caffeine ingested daily was not measured). A recent meta-analysis has shown that single-day cigarette smoking increases with $40-50 \%$ the relative risk of stroke or coronary heart disease in those who smoke 20 cigarettes a day [18]. With regard to alcohol consumption, Cox's simple analysis showed that alcohol users have a significantly lower risk of myocardial infarction (risk ratio [HR]: $0.44,95 \%$ confidence interval [Cl]: 0.21 , 0.92 ) and coronary artery disease (HR: $0.4,0.94)$ than nondrinkers [19]. Caffeine consumption of up to $600 \mathrm{mg}$ daily has been reported to have mild, transient and reversible effects on the cardiovascular system (increase of blood pressure, as well as activation of the sympathetic nervous system in nonhabitual coffee drinkers) [20,21].

The stress level was assessed by the patient's judgment; the prevalence of intense stress was $52.4 \%$. Reduced physical activity (73.1\%) was consistent with the presence of psoriasis and other cardiovascular risk factors. Stress can be considered a trigger and/ or aggravating factor in cardiovascular disease. Stress can cause myocardial infarction, cardiac arrhythmias, Takotsubo cardiomyopathy etc, especially during the panic attack [22]. A recent study has shown that increased levels of physical activity reduce the risk of developing cardiovascular disease [23]. Physically active women and men have a lower risk (25\% to $30 \%$ ) of developing stroke compared to physically inactive individuals [24].

A very recent cross-sectional survey, including 8261 patients with verified coronary artery events or interventions from 27 countries, regarding the prevalence of cardiovascular risk factors, found that $90 \%$ were smokers (we found only $71 \%$ in our study group), 38\% were obese and $59 \%$ had central obesity ( $80 \%$ of our patients were overweight and obese, with mean \pm SD waist circumference of $103.67 \pm 18.916 \mathrm{~cm}$ and BMI $28.27 \pm 5.091$ $\left.\mathrm{Kg} / \mathrm{m}^{2}\right)$. The same study found that $42 \%$ of the patients had a blood pressure $\geq 140 / 90 \mathrm{mmHg}$ (the mean \pm SD systolic blood pressure was $150.61 \pm 11.065 \mathrm{mmHg}$ in our study, and diastolic blood pressure $88.43 \pm 3.992 \mathrm{mmHg}), 71 \%$ had $\mathrm{LDL}$-cholesterol $\geq 70 \mathrm{mg} / \mathrm{dL}$ (our mean $\pm \mathrm{SD}$ was $44.11 \pm 12.434 \mathrm{mg} / \mathrm{dL}$ ) and $29 \%$ reported having diabetes (we found only $11 \%$ ) $[25,26]$.

Regarding triglycerides, we found mean $\pm S D$ values of $147.36 \pm 26.837 \mathrm{mg} / \mathrm{dL}$. A new study has found that triglycerides are modifiable atherosclerotic risk factors for cardiovascular disease [27].

Vitamin D is involved in cardiovascular physiology, its deficiency is associated with increased subclinical and overtcardiovascular disease $[28,29]$. Patients with psoriasis from our study group had vitamin $D$ deficiency (mean \pm SD $28.25 \pm 19.13 \mathrm{ng} / \mathrm{mL}$ ).

Regarding inflammatory markers, we found high levels of fibrinogen, associated with increased risk of coronary and cerebrovascular disease, in $47.6 \%$ of the patients with psoriasis. Elevated ESR values have been found in $39.4 \%$ of cases.

C-reactive protein represents a marker of the disease severity and cardiovascular risk in patients with psoriasis. The values of the C reactive protein in $49 \%$ of the cases represented an inflammatory process, in $33.2 \%$ the values represented a high cardiovascular risk and in $17.8 \%$ the values represented a moderate cardiovascular risk.

We found hypocalcemia in $49 \%$ of the patients from the study group, which may contribute to the development of stroke in these patients, as it was shown in one study, which revealed that serum calcium concentration is an independent risk factor for stroke and is associated with extracranial carotid atherosclerosis [30].

We found hypocalcemia in $49 \%$ of the patients from the study group. Calcium plays a key role in cardiac muscle contraction and metabolism, hypocalcemia being a reversible cause of heart failure [31].

\section{Conclusions}

Patients with psoriasis have a very high risk of developing life-long cardiovascular disease, because of a multitude of risk factors associated with psoriasis. Intervention on modifiable risk factors for cardiovascular disease can be mediated by a family doctor, who can monitor the development over time and may also intervene early when appropriate. A guideline for the prevention and monitoring of cardiovascular diseases in patients with psoriasis may be useful, especially for family physicians. 


\section{References}

1.GIBBS, S., Int J Dermatol., 35, no. 9, 1996, p. 633.

2.DANIELSEN, K., OLSEN, A.O., WILSGAARD, T., FURBERG, A.S., Br J

Dermatol., 168, no. 6, 2013, 1303.

3.RADULESCU, D., BALCANGIU STROESCU, A., PRICOP, C., GEAVLETE, B., NEGREI, C., BRATU, O., GINGHINA, O., VACAROIU, I. Rev Chim (Bucharest), 68, no. 1, 2017, p. 52-54.

4.NICULAE, A., PERIDE, I., MARINESCU-PANINOPOL, A., VRABIE, C.D., GINGHINA, O., JECAN, C.R., BRATU, O.G. Rom J Morphol Embryol, 57, no. 2, 2016, p. 591-594.

5.SPINU, D., BRATU, O., POPESCU, R., MARCU, D., RADULESCU, A., MISCHIANU, D. Romanian Journal of Military Medicine, 118, no. 3 , 2015, p. 12-15.

6.*** Global Health Estimates 2016: Deaths by Cause, Age, Sex, by Country and by Region, 2000-2016. Geneva, World Health Organization; 2018. https://www.who.int/healthinfo/global_burden_disease/ estimates/en/index1.html

7.PRODANOVICH, S., KIRSNER, R.S., KRAVETZ, J.D., MA, F., MARTINEZ, L., FEDERMAN, D.G., Arch Dermatol., 145, no. 6, 2009, p. 700. 8.RADULESCU, A., MADAN, V., AUNGURENCI, A., BRATU, O., FARCAS, C., DINU, M., MISCHIANU, D. Romanian Journal of Military Medicine, 118, no. 3, 2015, p. 20-22.

9.RUTTER, M., KANE, K., LUNT, M., CORDINGLEY, L., LITTLEWOOD, A., YOUNG, H., CHEW-GRAHAM, C., HILTON, R., SYMMONS, D., GRIFFITHS, C., Br J Dermatol., 175, no. 2, 2016, p. 348.

10.FERNANDEZ-ARMENTEROS, J., GÓMEZ-ARBONES, X., BUTI-SOLER, M., BETRIU-BARS, A., SANMARTIN-NOVELL, V., ORTEGA-BRAVO, M., J Eur Acad Dermatol Venereol., 33, no. 1, 2019, p. 128.

11.IRIMIE, M., OANTA, A., IRIMIE, C.A., FEKETE, L.G., MINEA, D.I., PASCU, A., Acta Dermatovenerol Croat., 23, no.1, 2015, p. 28.

12.DU BOIS, D., DU BOIS, E.F., Arch Intern Med (Chic)., XVII, no. 6(2), 1916, p. 863.

13.ASPLUND, K., KARVANEN, J., GIAMPAOLI, S., J OUSILAHTI, P., NIEMELA, M., BRODA, G., et al, Stroke., 40, no.7, 2009, p. 2319.

14.BENJAMIN, E.J., BLAHA, M.J., CHIUVE, S.E., CUSHMAN, M., DAS, S.R., DEO, R., Circulation, 135, no.10, 2017, p. e146.

15.PRODANOVICH, S., KIRSNER, R.S., KRAVETZ, J.D., MA, F., MARTINEZ, L., FEDERMAN, D.G., Arch Dermatol., 145, no. 6, 2009, p. 700.
16.GELFAND, J.M., NEIMANN, A.L., SHIN, D.B., WANG, X., MARGOLIS, D.J ., TROXEL, A.B., JAMA, 296, no. 14, 2006, p. 1735.

17.GELFAND, J.M., DOMMASCH, E.D., SHIN, D.B., AZFAR, R.S., KURD, S.K., WANG, X., TROXEL, A.B., J Invest Dermatol., 129, no. 10, 2009, p. 2411.

18.HACKSHAW, A., MORRIS, J.K., BONIFACE, S., TANG, J.L., MILENKOVI/E, D., BMJ, 360, 2018, p. j5855.

19.PARK, J., RYU, Y., CHO, S., Alcohol Clin Exp Res., 41, 2017, no. 2, p. 379.

20.TURNBULL, D., RODRICKS, J.V., MARIANO, G.F., FARAH CHOW DHURY, F., Regulatory Toxicology and Pharmacology, 89, 2017, p. 165.

21.SUCEVEANU, A.I., PANTEA STOIAN, A., PAREPA, I., Rev Chim (Bucharest), 69, no. 8, 2018, p. 2260-2267.

22.ESLER, M., Neurosci Biobehav Rev., 74, no. Pt B, 2017, p. 269.

23.HIDALGO-SANTAMARIA, M., BES-RASTROLLO, M., MARTINEZGONZALEZ, M.A., MORENO-GALARRAGA, L., RUIZ-CANELA, M., FERNANDEZ-MONTERO, A., Am J Cardiol., 122, no. 11, 2018, p. 1871. 24.*** US Department of Health and Human Services. Physical activity guidelines for Americans. 2008 http://www.health.gov/paguidelines/. Accessed 21.06.2018.

25.KOTSEVA, K., DE BACKER, G., DE BACQUER, D., RYDEN, L., HOES, A., GROBBEE, D., et al. Eur J Prev Cardiol., 2019, [Epub ahead of print] https://doi.org/10.1177/2047487318825350

26.PANTEA STOIAN, A., PITURU, S.M., HAINAROSIE, R., Farmacia, 66, no. 1, 2018, p. 1-7.

27.TADA, H., NOHARA, A., KAWASHIRI, M., Nutrients., 10, no. 11, 2018, p. 1789.

28.APOSTOLAKIS, M., ARMENI, E., BAKAS, P., LAMBRINOUDAKI, I., Maturitas., 115, 2018, p. 1.

29.PANTEA STOIAN, A., ELIAN, V., NITIPIR, C., et al. The $3^{\text {rd International }}$ Conference on Interdisciplinary Management of Diabetes Mellitus and its Complications (Interdiab), Bucharest, 2017. Diabetes Mellitus in Internal Medicine, 2017, p. 232-242.

30.KANG, K., Atherosclerosis, 232, no. 1, 2014, p. 249.

31.CATALANO, A., BASILE, G., LASCO, A., Aging Clin Exp Res., 24, no. 4, 2012, p. 400.

Manuscript received: 9.11 .2018 